\title{
Hypolipidemic effect of aqueous leaf extract of carmona microphylla G Don
}

\author{
Qibing Liu ${ }^{1}, \mathrm{Na} \mathrm{Lin}^{2}$, Daorui $\mathrm{Yu}^{1}$, Song Li ${ }^{1}$, Qiaoqin $\mathrm{Xu}^{1}, \mathrm{Xianjing} \mathrm{Qin}^{1}$, Juntao \\ Zeng $^{3 *}$ and Yu Zeng ${ }^{1}$ \\ ${ }^{1}$ Department of Pharmacology, Hainan Medical University, School of Pharmaceutical Science, ${ }^{2}$ Department of Pharmacy, The \\ General Hospital of People's Liberation Army (187 Hospital), ${ }^{3}$ Department of Gastroenterology, Affiliated Hospital of Hainan \\ Medical University, Haikou, China
}

*For correspondence: Email: zengjuntaohyfy@sina.com; Tel: +86-898-31350701; Fax: +86-898-31350701

Received: 13 October 2015

Revised accepted: 1 July 2016

\begin{abstract}
Purpose: To investigate the hypolipidemic effects of the aqueous leaf extract of Carmona microphylla (Lam.) G. Don. (CAE) in vitro and in vivo.

Methods: The lipid-lowering effect of CAE was investigated in oleic acid (OA)-induced steatosis in HepG2 liver cells, as well as in high-fat diet (HFD)- and triton WR-1339 (TRI)-induced hyperlipidemic mice. The levels of intracellular, serum and/or hepatic total cholesterol (TC); triglyceride (TG); low density lipoprotein-cholesterol (LDL-c); high density lipoprotein-cholesterol (HDL-c); hepatic superoxide dismutase (SOD) activity and malondialdehyde (MDA) were determined by oil-red $O$ staining and appropriate kits.

Results: Treatment with CAE inhibited lipid accumulation in HepG2 cells and reduced the elevated levels of serum TC, TG and LDL-C as well as hepatic TC and TG in hyperlipidemic mice induced by HFD. CAE administration also significantly decreased arteriosclerosis index (Al) and LDL-C/HDL-c ratio, but improved oxidative status as revealed by increased hepatic SOD activity and decreased MDA level. The lipid ameliorating and antioxidative effects of CAE (600 mg/kg) were comparable to those of the standard lipid-lowering drug, sivastatin $(5 \mathrm{mg} / \mathrm{kg})$.

Conclusion: These results suggest that C. microphylla aqueous extract (CAE) protects against hyperlipidemia induced by HFD in mice and may find therapeutic application in hyperlipidemic patients.
\end{abstract}

Keywords: Carmona microphylla, Hyperlipidemia, Atherosclerosis, Oxidative stress, Sivastatin, Lipidlowering

\begin{abstract}
Tropical Journal of Pharmaceutical Research is indexed by Science Citation Index (SciSearch), Scopus, International Pharmaceutical Abstract, Chemical Abstracts, Embase, Index Copernicus, EBSCO, African Index Medicus, JournalSeek, Journal Citation Reports/Science Edition, Directory of Open Access Journals (DOAJ), African Journal Online, Bioline International, Open-J-Gate and Pharmacy Abstracts
\end{abstract}

\section{INTRODUCTION}

Hyperlipidemia, characterized by elevated levels of total serum cholesterol (TC), triglycerides (TG) and low density lipoprotein-cholesterol (LDL-C), is a major risk factor for the development of coronary artery disease and the progression of atherosclerotic lesions [1,2]. High levels of cholesterol, especially LDL-c, may attach to the walls of blood vessels (if the quantity of HDL is insufficient) to form oxidized LDL, which is highly atherogenic and toxic to vascular cells, leading to a variety of serious diseases including atherosclerosis $[3,4]$.

In hyperlipidemic condition, the activities of superoxide dismutase (SOD) and catalase (CAT) are decreased, which leads to pronounced elevation of reactive oxygen species (ROS), such as malondialdehyde (MDA), and causes vascular 
and tissue damage $[5,6]$. Although numerous synthetic lipid-lowering drugs, such as statins, fibrates, niacin, and bile acid sequestrants (resins), are available for combating hyperlipidemia, management of this disorder without accompanying side effects remains a major challenge. Therefore, it is necessary to find drugs with lipid lowering and antioxidant activities that produce little or no side effects. Generally, natural products are the preferred option, and a number of herbal medicines from plants and vegetables have been reported to control hyperlipidemia and related complications in patients [7-12].

Carmona microphylla (Lam.) G. Don., commonly known as Ehretia buxifolia Roxb. and also called "Fujian Cha" in China, is widely distributed in the Guangdong, Hainan, and Taiwan provinces of South China, as well as in subtropical areas of southern and south-eastern Asia [13]. The root of C. microphylla has long been used to treat cachexia and venereal infections and is an antidote to food poisoning $[14,15]$. In the Hainan province of South China, the leaves of $C$. microphylla have been used as a folk medicine for the treatment of hyperlipidemia and diabetes. However, the pharmacological effects of $C$. microphylla have not been validated by scientific studies. In the present work, the antihyperlipidemic and antioxidant effects of an aqueous extract of $C$. microphylla leaves (CAE) were investigated in oleic acid (OA)-induced steatosis in HepG2 liver cells and in high-fat diet (HFD)-induced hyperlipidemic mice.

\section{EXPERIMENTAL}

\section{Reagents}

Triton WR-1339, oleic acid, sivastatin and atorvastatin were purchased from Sigma Chemical Co. (St. Louis, MO, USA). All other chemicals and reagents used were of analytical grade and were obtained from Sinopharm Chemical Reagent Co., Ltd (Beijing, China).

\section{Preparation of C. microphylla leaf extract}

Fresh leaves of C. microphylla were collected in May 2013 from Haikou City, Hainan Province, China and were identified by Prof. Niankai Zeng of the College of Pharmacy, Hainan Medical University. A voucher specimen was deposited in the Hainan Medical University herbarium (no. HMU-ETHPH-FJC-1305) for future reference. Freshly harvested leaves were dried and finely powdered. Fifty grams of the powder were extracted with $800 \mathrm{~mL}$ of distilled water using a
Soxhlet apparatus. The residue thus obtained was then filtered, and the resulting filtrate was concentrated to a dry mass by vacuum distillation; this was used as the $C$. microphylla aqueous extract (CAE).

\section{Ethics statement}

This study was carried out in strict accordance with the recommendations of the Guide for the Care and Use of Laboratory Animals [16]. All procedures with animals were approved by the Institutional Animal Ethical Committee of Hainan Medical University (ref nos. HMU20130135 and HMU20150323).

\section{Experimental animals}

Healthy female C57BL/6 mice (18-22 g) were housed under conditions of controlled temperature $\left(25 \pm 2{ }^{\circ} \mathrm{C}\right)$ with a 12-h/12-h daynight cycle, during which time, they had free access to food and water ad libitum. The animals were allowed to acclimatize for 5 days before commencing the experiments.

\section{Evaluation of anti-hyperlipidemic effect}

\section{HFD-induced hyperlipidemia model}

Animals were divided into six groups consisting of eight animals each. The control group was fed with a normal diet, while the other groups were fed with a high fat-diet (HFD). The normal rodent chow contained $12 \%$ fat, $62 \%$ carbohydrate, and $26 \%$ protein, with a total energy content of $12.6 \mathrm{~kJ} / \mathrm{g}$. The HFD was formulated to balance micronutrient content on a calorie basis and contained $60 \%$ fat, $26 \%$ carbohydrate, and 14 $\%$ protein, with a total energy content of 21.0 $\mathrm{kJ} / \mathrm{g}$. The HFD contained much less choline bicitrate $(0.6 \mathrm{~g} / \mathrm{kg})$ and DL-methionine $(1.5 \mathrm{~g} / \mathrm{kg})$ than the normal rodent chow. The fatty acid composition of the fats (mainly from lard) in the HFD was $36 \%$ saturated fatty acids, $45 \%$ monounsaturated fatty acids, and $19 \%$ polyunsaturated fatty acids (PUFA). The sivastatin group was treated with $5 \mathrm{mg} / \mathrm{kg}$ sivastastin, while the CAE groups were treated with different doses of $\operatorname{CAE}(10,50$ and $100 \mu \mathrm{g} / \mathrm{mL}$ ). At the end of the 4-week period, animals were sacrificed after an overnight fast. Blood and liver samples were then collected for the lipid profile and oxidative status.

\section{Triton WR-1339-induced hyperlipidemia model}

Animals were divided into five groups, consisting of eight animals each, and treated as follows. A 
normal control group was treated with vehicle (distilled water), while a TRI control group was given equal volume of distilled water and served as a negative control. The TRI + atorvastatin and TRI + CAE groups were treated with atorvastatin (5 mg/kg body weight) and CAE (300 and 600 $\mathrm{mg} / \mathrm{kg}$ body weight), respectively. The extract and atorvastatin were administered by oral gavage. After 7 days of treatment, the normal control group was injected with equal volume of distilled water while all other groups were hyperlipidemia-induced by a single intraperitoneal (ip) injection of triton WR-1339 (300 $\mathrm{mg} / \mathrm{kg}$ body weight) dissolved in normal saline ( $\mathrm{pH} 7.4)$. Animals were sacrificed $24 \mathrm{~h}$ after the injection. Blood was collected directly from the heart of each animal, and the serum was separated and used for the serum lipid profile.

\section{Determination of serum lipid profile}

TC, TG, LDL-c and HDL-c were enzymatically determined using commercial kits (BioSino Biotechnology and Science Inc., Beijing, China). Arteriosclerosis index $(\mathrm{Al})$ was calculated as in Eq 1.

$\mathrm{Al}=(\mathrm{TC}-\mathrm{HDL}-\mathrm{C}) / \mathrm{HDL}-\mathrm{C}$

\section{Determination of hepatic antioxidant status}

The liver was excised and washed thoroughly in ice-cold saline to remove blood. Ten percent homogenate was prepared in phosphate buffer (0.05 M, pH 7) using a polytron homogenizer. The homogenate was centrifuged at $3000 \mathrm{~g}$ for $20 \mathrm{~min}$ to remove cell debris and nuclei, and the supernatant was centrifuged at $9000 \mathrm{~g}$ for $20 \mathrm{~min}$ to remove mitochondria. The supernatant was used for the determination of hepatic levels of MDA, activity of liver SOD, and total protein using a commercial kit (BioSino Bio-technology and Science Inc., Beijing, China).

\section{Cell-based lipid accumulation assay}

HepG2 cells were maintained in DMEM (Dulbecco's Modified Eagle Medium) supplemented with $10 \%$ fetal bovine serum and penicillin/streptomycin $(100 \mu \mathrm{g} / \mathrm{mL})$. The cells with $70 \%-80 \%$ confluence were incubated in DMEM + oleic acid (100 $\mu \mathrm{M})$ for $12 \mathrm{~h}$ and were then treated with $\mathrm{CAE}$ (as indicated) and the positive control sivastatin (5 $\mu \mathrm{g} / \mathrm{mL})$ in DMEM/100 $\mu \mathrm{M}$ oleic acid, with DMEM/100 $\mu \mathrm{M}$ oleic acid as a blank for an additional $6 \mathrm{~h}$. Subsequently, the cells were subjected to oil-red $\mathrm{O}$ staining or TC and TG determination as described previously. Each experiment $(n=8$ for oil-red $\mathrm{O}$ staining or $\mathrm{n}=3$ for $\mathrm{TC}$ and $\mathrm{TG}$ determination) was repeated in triplicate.

\section{Statistical analysis}

Data are expressed as the mean \pm SEM. Oneway analysis of variance (ANOVA) followed by Tukey's test was used for statistical analysis. SPSS (version 16) statistical software was used for the analysis of data, and $p<0.05$ was considered statistically significant.

\section{RESULTS}

\section{CAE inhibited lipid accumulation in HepG2 cells}

As shown in Figure 1, supplementation with $\mathrm{OA}$ significantly increased lipid accumulation in HepG2 cells. Treatment with CAE decreased OA-elicited neutral lipid accumulation (Figure $1 A, B)$ as well as the intracellular contents of TC (Figure 1C) and TG (Figure 1D) in a dosedependent manner. This inhibitory effect on lipid metabolism was independent of the cytotoxic effect of CAE on HepG2 cells as revealed by an MTT assay (data not shown).

Effect of CAE on the serum lipid profile in high-fat diet (HFD)-induced hyperlipidemic mice

Serum TC, TG and LDL-c levels were significantly elevated $(p<0.001)$ in the HFDtreated groups (Figure 2A). Oral administration of $\mathrm{CAE}$ to mice resulted in significant decrease of serum TC, TG and LDL-c. The HDL level was increased but not significant when compared to the control group. The lipid-lowering efficacy of $\mathrm{CAE}$ at $600 \mathrm{mg} / \mathrm{kg}$ was comparable to that of the standard reference drug sivastatin (5 $\mathrm{mg} / \mathrm{kg}$ ) (Figure 2A). Simultaneously, the atherogenic index $(\mathrm{Al})$ and $\mathrm{LDL}-\mathrm{C} / \mathrm{HDL}-\mathrm{C}$ ratio were significantly increased in HFD mice and declined after treatment with $\mathrm{CAE}$ for 4 weeks. The efficacy of CAE at $600 \mathrm{mg} / \mathrm{kg}$ was also comparable to that of sivastatin $(5 \mathrm{mg} / \mathrm{kg}$ ) (Figure 2B).

\section{Effect of CAE on hepatic TC and TG levels in HFD-induced hyperlipidemic mice}

Consumption of CAE markedly reduced the liver content of TC $(5.27 \%, 14.14 \%$ and $24.91 \%$ by 200, 400 and $600 \mathrm{mg} / \mathrm{kg}$ CAE, respectively) (Figure 3A) and TG (15.72 \%, 28.01\% and 40.11 $\%$ by 200,400 and $600 \mathrm{mg} / \mathrm{kg}$ CAE, respectively) (Figure 3B). At these doses, the efficacy of CAE 
in decreasing hepatic TC and TG was comparable to that of $5 \mathrm{mg} / \mathrm{kg}$ sivastatin, especially in decreasing hepatic TG (Figure 3B).

Effect of CAE on the hepatic antioxidant status

The activity of the antioxidant enzyme SOD was significantly lowered while the hepatic level of
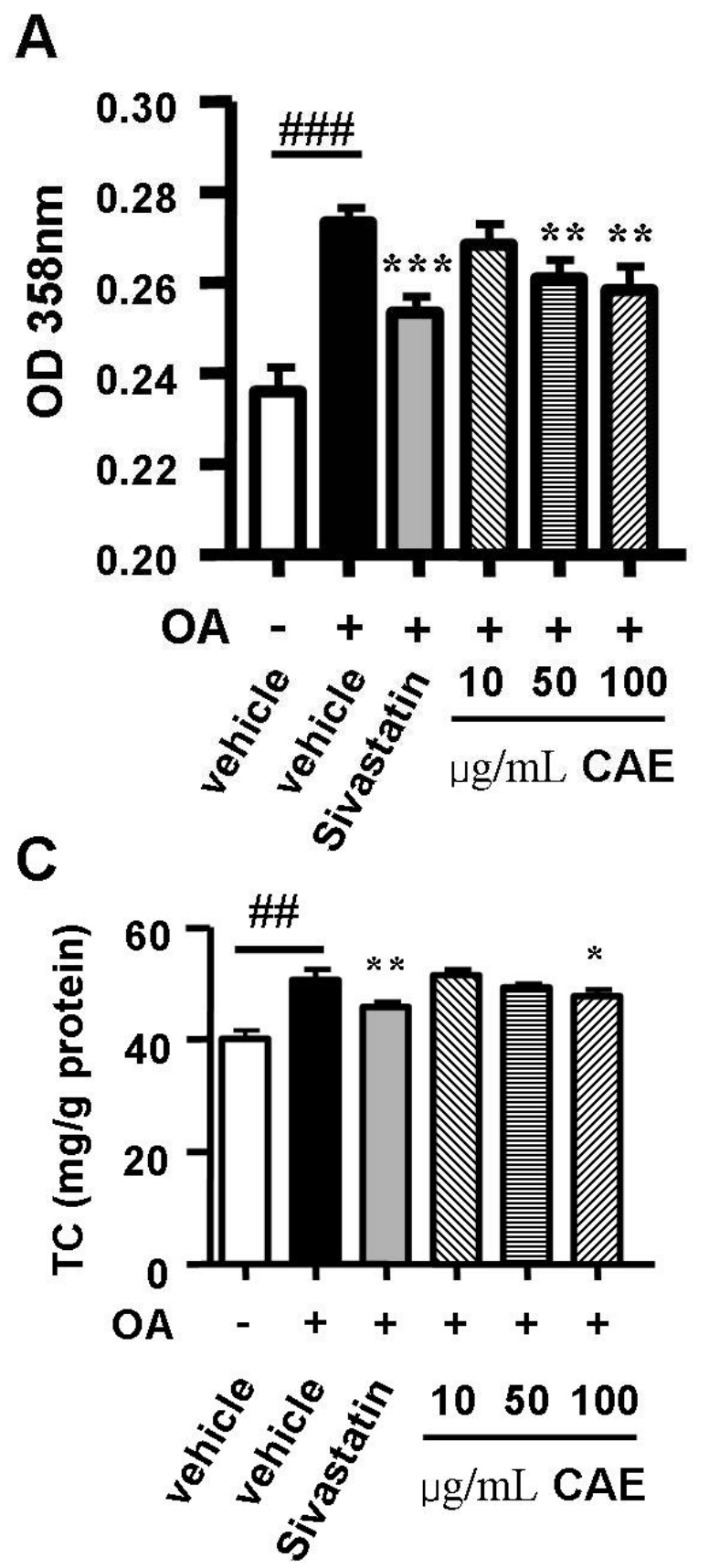

MDA was significantly increased in the livers of mice treated with HFD (Figure 4). The CAE treatment improved the activity of SOD and decreased MDA concentration in the liver. The hepatic SOD activity and MDA levels were restored to normal control levels in CAE-treated animals at the dose of $600 \mathrm{mg} / \mathrm{kg}$ (Figure 4).

B
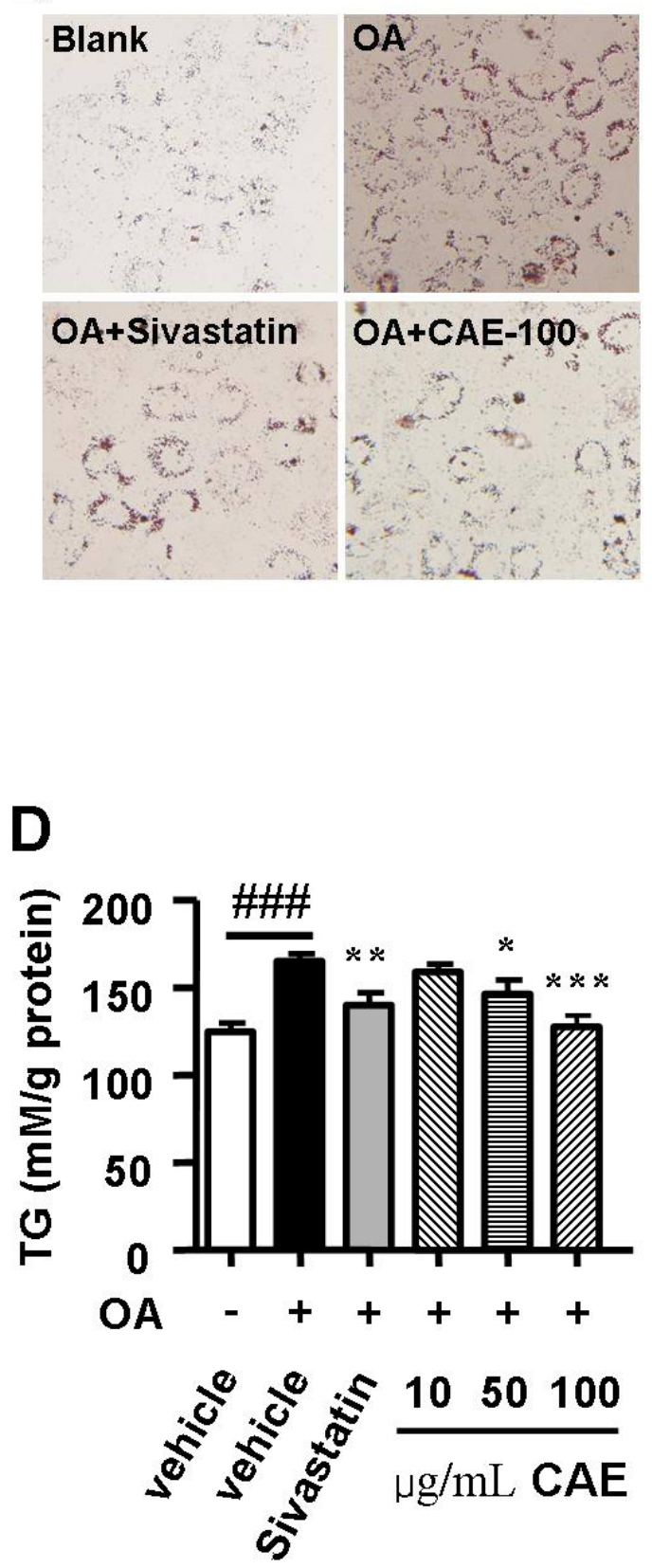

Figure 1: Effect of C. microphylla aqueous extract (CAE) on oleic acid (OA)-elicited lipid accumulation in HepG2 cells. OD $358 \mathrm{~nm}$ after oil-red O staining (A); images of oil-red O staining (400X) (B); intracellular levels of TC (C) and TG (D). The dosage for sivastatin is $5 \mu \mathrm{g} / \mathrm{mL}$. The values represent the mean \pm SEM. The results are representative of three different experiments; ${ }^{\# \#} p<0.01,{ }^{\# \#} p<0.001$ vs blank group, ${ }^{*} p<0.05,{ }^{* *} p<0.01,{ }^{* \star *} p<$ 0.001 vs oleic acid group. OA: oleic acid; CAE: C. microphylla aqueous extract 

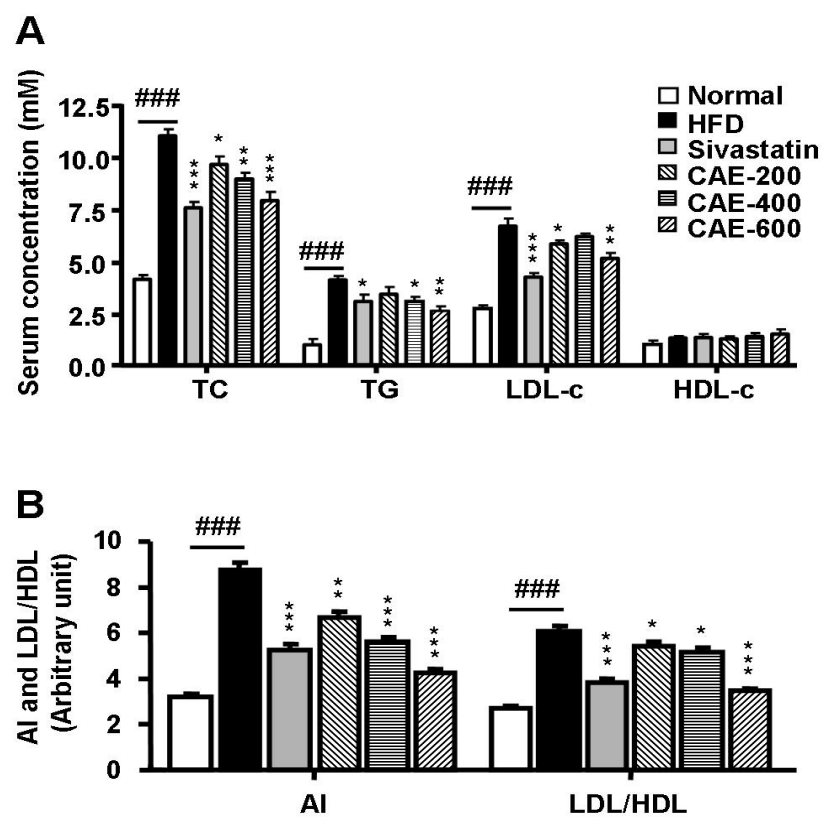

Figure 2: Effect of $C$. microphylla aqueous extract (CAE) on the serum lipid profile in high-fat diet (HFD)-induced hyperlipidemic mice. Effect of CAE on the serum lipid profile (A); effect of CAE on the atherogenic index (AI) and LDL-C/HDL-c ratio (B). Eight animals in each group. The dosages are as follows: sivastatin (5 mg/kg); CAE (200, 400 or $600 \mathrm{mg} / \mathrm{kg}$ as indicated). The values represent the mean $\pm \mathrm{SEM}$; ${ }^{\# \#} p<0.001$ normal control group vs HFD group, ${ }^{*} p<0.05,{ }^{* *} p<0.01,{ }^{* \star *} p<0.001$ test groups vs HFD group

A

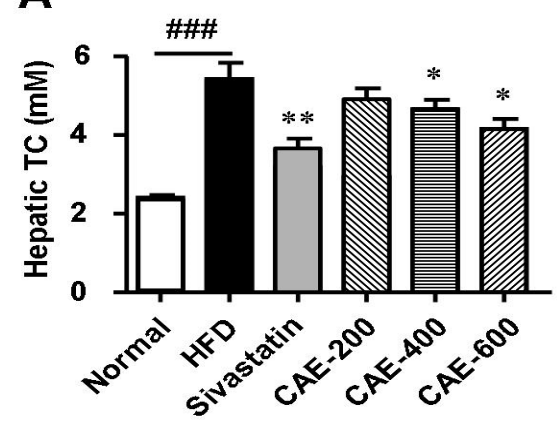

B

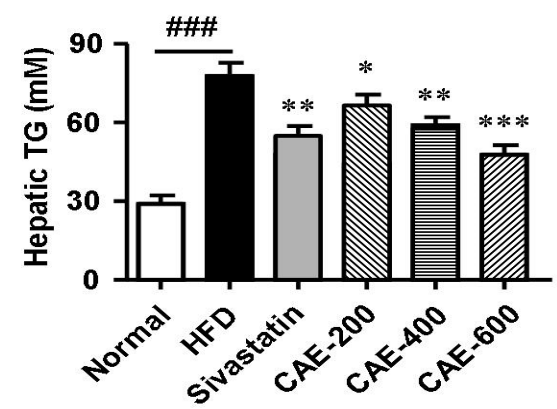

Figure 3: Effect of $C$. microphylla aqueous extract (CAE) on liver TC (A) and TG (B) in high-fat diet (HFD)-induced hyperlipidemic mice. The dosages are as follows: sivastatin ( $5 \mathrm{mg} / \mathrm{kg}$ ); CAE (200, 400 or 600 $\mathrm{mg} / \mathrm{kg}$, as indicated). The values represent the mean \pm SEM; ${ }^{\# \#} p<0.001$ normal control group vs HFD group, ${ }^{*} p<0.05,{ }^{* *} p<0.01,{ }^{* * *} p<0.001$ test groups vs HFD group

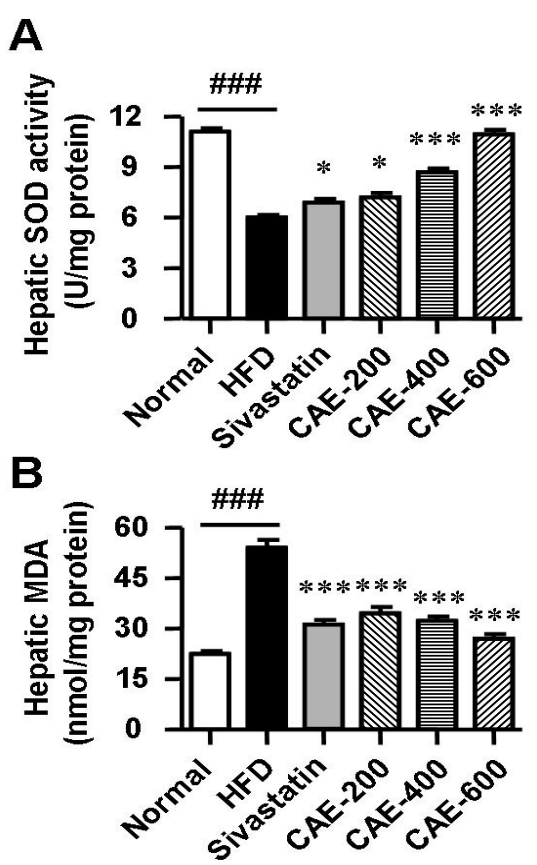

Figure 4: Effect of C. microphylla aqueous extract (CAE) on the activity of liver SOD (A) and hepatic levels of MDA (B) in high-fat diet (HFD)-induced hyperlipidemic mice. The dosages are as follows: sivastatin (5 mg/kg); CAE (200, 400 or $600 \mathrm{mg} / \mathrm{kg}$, as indicated). The values represent the mean \pm SEM; ${ }^{\# \#} p$ $<0.001$ normal control group vs HFD group, ${ }^{*} p<0.05$, ${ }^{* *} p<0.001$ test groups vs HFD group 


\section{Effect of CAE on serum TC and TG in Triton WR-1339-induced dyslipidemic mice}

Serum TC and TG levels were significantly elevated in TRI treated groups (Figure 5). Treatment with CAE significantly decreased serum TC and TG. The levels of TC and TG were decreased approximately $47.78 \%$ and $49.94 \%$ in the case of $300 \mathrm{mg} / \mathrm{kg}$ and $55.96 \%$ and $74.90 \%$ in the case of $600 \mathrm{mg} / \mathrm{kg} \mathrm{CAE}$ treated groups, respectively, compared to the TRI control (Figure 5). The standard reference drug atorvastatin $(5 \mathrm{mg} / \mathrm{kg})$ showed $53.66 \%$ and $71.00 \%$ decreases for TC and TG, respectively (Figure 5).

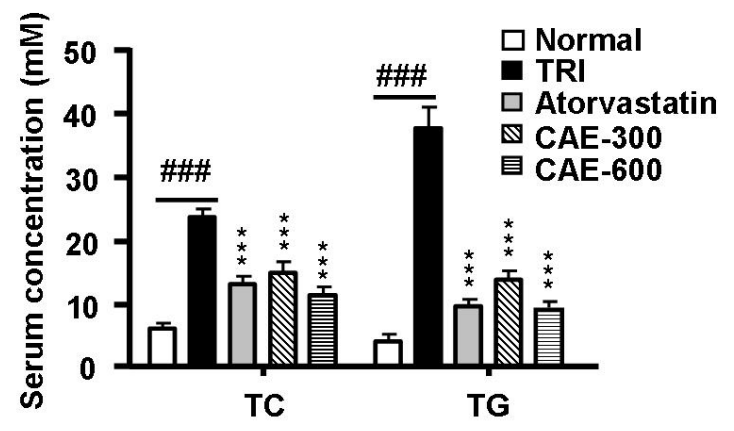

Figure 5: Effect of C. microphylla aqueous extract (CAE) on serum TC and TG in Triton-WR-1339 (TRI)induced hyperlipidemic mice. The dosages are as follows: Triton-WR-1339 (TRI, i.p. 300 mg/kg); atorvastatin (p.o. $5 \mathrm{mg} / \mathrm{kg}$ ); C. microphylla aqueous extract (CAE, p.o. 600 or $300 \mathrm{mg} / \mathrm{kg}$, as indicated). The values represent the mean \pm SEM; ${ }^{\# \#} p<0.001$ TRI control vs normal control group; ${ }^{* \star *} p<0.001$ test groups vs TRI control group

\section{DISCUSSION}

The incidence of hyperlipidemia is increasing at a dramatic rate throughout the world [8]. The leaves of Carmona microphylla (Lam.) G. Don. have been used for the treatment of hyperlipidemia in the Hainan province of South China for hundreds of years. However, the pharmacological effects of C. microphylla have not been validated by scientific studies.

In this study, the lipid-lowering effects of $C$. microphylla aqueous extract (CAE) were first demonstrated in OA-induced steatosis in HepG2 liver cells. Treatment with CAE $(100 \mu \mathrm{g} / \mathrm{mL})$ significantly inhibited lipid accumulation induced by oleic acid in HepG2 cells and largely reduced the intracellular levels of TC and TG with an efficacy comparable to $10 \mu \mathrm{g} / \mathrm{mL}$ of the approved drug sivastatin.
Further evidence was shown in HFD-induced dyslipidemic mice to test the antihyperlipidemic effects of CAE. As is well-known, elevated levels of serum TC, TG and LDL-c, accompanied by reduced HDL-c levels, are frequently associated with an increased risk of coronary heart disease and atherosclerosis [2,17]. The deposition of LDL-C in the blood vessel walls is a major component of atherosclerotic plaque lesions. Moreover, LDL-c is susceptible to oxidative modification, and this oxidative modification of LDL-C is causally involved in the initiation and promotion of atherosclerosis [18]. Hence, decreasing serum TC, TG and LDL-C levels is important for reducing the risk of atherosclerosis. Treatment with CAE once daily for 4 weeks can effectively decrease the level of serum TC, TG and LDL-c. Hence, through the hypolipidemic effect, this plant extract experimentally supported its efficacy in preventing the early event in atheroma formation. The efficacy of CAE (600 $\mathrm{mg} / \mathrm{kg}$ ) in decreasing serum TC and LDL-C was slightly weaker than sivastatin $(5 \mathrm{mg} / \mathrm{kg})$ but more potent in decreasing TG. These results indicate a discrepancy between CAE and statins in lipid-lowering action.

The non-ionic detergent Triton WR-1339 can block the uptake of TG-rich lipoproteins from plasma by peripheral tissues, leading to acute hyperlipidemia in animals. It is widely used, particularly in mice, for screening natural or chemical hypolipidemic drugs [16, 19-20]. In the present study, TC and TG levels were largely elevated $24 \mathrm{~h}$ after the triton WR-1339 administration, which was significantly decreased by the treatment with CAE. These findings suggest that the cholesterol-lowering activity of $\mathrm{CAE}$ may act through the enhanced catabolism of TC, TG and LDL-C.

HDL carries cholesterol and cholesterol esters from the peripheral tissues and cells to the liver, where cholesterol is metabolized into bile acids. This pathway plays an important role in reducing cholesterol levels in the blood and peripheral tissues and in inhibiting atherosclerotic plaque formation in the aorta [21-22]. The atherogenic index and LDL-C/HDL-c ratio are thus important diagnostic indicators of the risk of atherosclerosis development [23]. In the present study, administration of CAE slightly increased serum HDL-C and significantly decreased TC and LDL-C levels, thus significantly reducing the Al and LDLc/HDL-c ratio. This ameliorative action provides support for using CAE to prevent atheroma formation. Interestingly, the decrease of the Al 
and $\mathrm{LDL} / \mathrm{HDL}$ ratio by $\mathrm{CAE}$ at $600 \mathrm{mg} / \mathrm{kg}$ was more pronounced than that resulting from sivastatin $(5 \mathrm{mg} / \mathrm{kg})$ treatment, indicating a beneficial role for drinking CAE for the prevention of atherosclerosis.

Oxidative stress has been implicated in many diseases including arteriosclerosis. Living tissues are endowed with innate antioxidant defense mechanisms, including the SOD, which is involved in the disposal of superoxides and hydrogen peroxide $\left(\mathrm{H}_{2} \mathrm{O}_{2}\right)$. A reduction in the activity of SOD is associated with the accumulation of highly reactive free radicals, which leads to deleterious effects such as loss of integrity and function of cell membranes [24]. In the present study, the activity of SOD in hepatic tissue samples from hyperlipidemia-induced, distilled water-treated mice was significantly lower than that of normal control mice. Administration of CAE significantly enhanced the activity of SOD in the liver and was more potent than sivastatin and similar to other popular teas.

Lipid peroxidation, a free radical-mediated propagation of oxidative insult to polyunsaturated fatty acids, is a characteristic feature of hyperlipidemia; it impairs cell membrane fluidity and alters the activity of membrane-bound enzymes and receptors, resulting in membrane malfunction $[25,26]$. The observed elevated mean levels of MDA in HFD control mice possibly resulted from increased intensity of lipid peroxidation, which has been reported to occur from intensified free radical production [27]. Oral administration of CAE to hyperlipidemic mice resulted in significantly lower mean levels of MDA than that of distilled water-treated hyperlipidemic mice. CAE possibly up-regulated hepatic SOD activity, thereby preventing oxidative modification of lipoprotein, thus leading to a reduction in MDA levels.

\section{CONCLUSION}

The present study has demonstrates for the first time the putative lipid-lowering and antioxidant activity of aqueous leaf extract of C. microphylla in oleic acid-elicited HepG2 liver cells and HFDas well as Triton WR-1339-induced hyperlipidemic mice. The lipid-lowering potential and antioxidant capacity of CAE at a dose of 600 $\mathrm{mg} / \mathrm{kg}$ appeared to be as effective as that of the standard lipid-lowering drug, simvastatin, at a dose of $5 \mathrm{mg} / \mathrm{kg}$. Hence, CAE can potentially be developed as an alternative cholesterol-lowering drug for clinical use.

\section{DECLARATIONS}

\section{Acknowledgement}

The financial assistance given by National Natural Science Foundation of China (no. 81460550 ) is gratefully acknowledged. The authors are also grateful to Hainan Provincial Project of Modernization of Traditional Chinese Medicine (nos. ZY201426) and Hainan Provincial Key Project of Science and Technology Program (no. ZDXM2014070) for financial support.

\section{Conflict of Interest}

No conflict of interest associated with this work.

\section{Contribution of Authors}

The authors declare that this work was done by the authors named in this article and all liabilities pertaining to claims relating to the content of this article will be borne by them.

\section{REFERENCES}

1. Soh J, lqbal J, Queiroz J, Fernandez-Hernando C, Hussain MM. MicroRNA-30c reduces hyperlipidemia and atherosclerosis in mice by decreasing lipid synthesis and lipoprotein secretion. Nat Med 2013; 19: 892-900.

2. Ross R, Harker L. Hyperlipidemia and atherosclerosis. Science 1976; 193: 1094-1100.

3. LiX, Zhu M, Penfold ME, Koenen RR, Thiemann A, Heyll K, Akhtar S, Koyadan S, Wu Z, Gremse F, et al. Activation of CXCR7 limits atherosclerosis and improves hyperlipidemia by increasing cholesterol uptake in adipose tissue. Circulation 2014; 129: 1244-1253.

4. Keren P, George J, Shaish A, Levkovitz H, Janakovic Z, Afek A, Goldberg I, Kopolovic J, Keren G, Harats D. Effect of hyperglycemia and hyperlipidemia on atherosclerosis in $L D L$ receptor-deficient mice: establishment of a combined model and association with heat shock protein 65 immunity. Diabetes 2000; 49: 1064-1069.

5. El-Demerdash FM, Nasr HM. Antioxidant effect of selenium on lipid peroxidation, hyperlipidemia and biochemical parameters in rats exposed to diazinon. $J$ Trace Elem Med Biol 2014; 28: 89-93.

6. Samarghandian $S$, Borji $A$, Delkhosh MB, Samini $F$. Safranal treatment improves hyperglycemia, hyperlipidemia and oxidative stress in streptozotocininduced diabetic rats. J Pharm Pharm Sci 2013; 16: 352-362.

7. Wu C, Li Y, Chen Y, Lao X, Sheng L, Dai R, Meng W, Deng Y. Hypoglycemic effect of Belamcanda chinensis leaf extract in normal and STZ-induced diabetic rats and 
its potential active faction. Phytomedicine 2011; 18: 292297.

8. Zhang $X, W u C, W u H$, Sheng $L$, Su $Y$, Luan $H$, Sun $G$, Sun $X$, Tian $Y$, Ji $Y$, Guo $P, X u X$. Anti-hyperlipidemic effects and potential mechanisms of action of the caffeoylquinic acid-rich Pandanus tectorius fruit extract in hamsters fed a high fat-diet. PLoS One 2013; 8: e61922.

9. Zhao H, Lv F, Meng W, Dang H, Sun Z, Chen Y, Dai R, Deng $Y$, Wu C. Anti-hyperlipidemic effect of flavone-rich Belamcanda chinensis (L.) DC. (Iridaceae) leaf extract in ICR mice fed high-Fat Diet. Trop J Pham Res 2014; 13: 1653-1658.

10. Wu C, Zhang $X$, Luan $H$, Sun $G$, Sun $X$, Wang $X$, Guo $P$, $X u X$. The caffeoylquinic acid-rich Pandanus tectorius fruit extract increases insulin sensitivity and regulates hepatic glucose and lipid metabolism in diabetic $\mathrm{db} / \mathrm{db}$ mice. J Nutr Biochem 2014; 25: 412-419.

11. Zhang QY, Pan Y, Wang R, Kang LL, Xue QC, Wang XN, Kong LD. Quercetin inhibits AMPKITXNIP activation and reduces inflammatory lesions to improve insulin signaling defect in the hypothalamus of high fructose-fed rats. J Nutr Biochem 2014; 25: 420-428.

12. Wu C, Guo $Y$, Su $Y$, Zhang $X$, Luan $H$, Zhu $H$, He $H$, Wang $X$, Sun $G$, Sun $X$, Guo $P$, Zhu P. Cordycepin activates AMP-activated protein kinase (AMPK) via interaction with the gamma1 subunit. J Cell Mol Med 2014; 18: 293-304.

13. Roeder E, Wiedenfeld $H$. Plants containing pyrrolizidine alkaloids used in the traditional Indian medicine-including ayurveda. Pharmazie 2013; 68: 83-92.

14. Ganesan S. Traditional oral care medicinal plants survey of Tamil Nadu. Indian J Nat Prod Res 2008; 7: 166-172.

15. Zheng XL, Wei JH, Sun W, Li RT, Liu SB, Dai HF. Ethnobotanical study on medicinal plants around Limu Mountains of Hainan Island, China. J Ethnopharmacol 2013; 30: 964-974.

16. National Research Council of the National Academies. Guide for the care and use of laboratory animals. Washington, D.C: 2001.

17. Rony KA, Ajith TA, Nima $N$, Janardhanan $K K$. Hypolipidemic activity of Phellinus rimosus against triton WR-1339 and high cholesterol diet induced hyperlipidemic rats. Environ Toxicol Pharmacol 2014; 37: 482-492.

18. Wu C, Luan H, Zhang $X$, Wang S, Zhang $X$, Sun $X$, Guo $P$. Chlorogenic acid protects against atherosclerosis in
ApoE-/- mice and promotes cholesterol efflux from RAW264.7 macrophages. PLoS One 2014; 9: e95452.

19. Anandhi R, Annadurai T, Anitha TS, Muralidharan AR, Najmunnisha K, Nachiappan V, Thomas PA, Geraldine $P$. Antihypercholesterolemic and antioxidative effects of an extract of the oyster mushroom, Pleurotus ostreatus, and its major constituent, chrysin, in Triton WR-1339induced hypercholesterolemic rats. J Physiol Biochem 2013; 69: 313-323.

20. Oh PS, Lee SJ, Lim KT. Hypolipidemic and antioxidative effects of the plant glycoprotein (36 kDa) from Rhus verniciflua stokes fruit in Triton WR-1339-induced hyperlipidemic mice. Biosci Biotechnol Biochem 2006; 70: 447-456.

21. Rohatgi A, Khera A, Berry JD, Givens EG, Ayers CR, Wedin KE, Neeland IJ, Yuhanna IS, Rader DR, de Lemos JA, Shaul PW. HDL Cholesterol Efflux Capacity and Incident Cardiovascular Events. $N$ Engl J Med 2014; 371: 2383-2393.

22. Rader DJ, Hovingh GK. HDL and cardiovascular disease. Lancet 2014; 384: 618-625.

23. Sinning C, Kieback A, Wild PS, Schnabel RB, Ojeda F, Appelbaum S, Zeller $T$, Lubos E, Schwedhelm E, Lackner KJ, Debus ES, Munzel T, Blankenberg S, Espinola-Klein C. Association of multiple biomarkers and classical risk factors with early carotid atherosclerosis: results from the Gutenberg Health Study. Clin Res Cardiol 2014; 103: 477-485.

24. Le Lay S, Simard G, Martinez MC, Andriantsitohaina R. Oxidative stress and metabolic pathologies: from an adipocentric point of view. Oxid Med Cell Longev 2014; doi: 10.1155/2014/908539.

25. Ryder E, Pedreanez A, Vargas R, Pena C, Fernandez E, Diez-Ewald M, Mosquera J. Increased proinflammatory markers and lipoperoxidation in obese individuals: Inicial inflammatory events? Diabetes Metab Syndr 2014; doi: 10.1016/j.dsx.2014.04.022.

26. Abliz A, Aji Q, Abdusalam E, Sun X, Abdurahman A, Zhou W, Moore N, Umar A. Effect of Cydonia oblonga Mill. leaf extract on serum lipids and liver function in a rat model of hyperlipidaemia. J Ethnopharmacol 2014; 151: $970-974$.

27. Gawlik M, Gawlik MB, Brandys J. The impact of Triton WR-1339 induced hyperlipidemia on the effects of benzo(a)pyrene or guaiacol on alpha- and gammatocopherol pools and selected markers of proantioxidative balance in rat plasma and erythrocytes. Environ Toxicol Pharmacol 2012; 33: 386-393.yu 